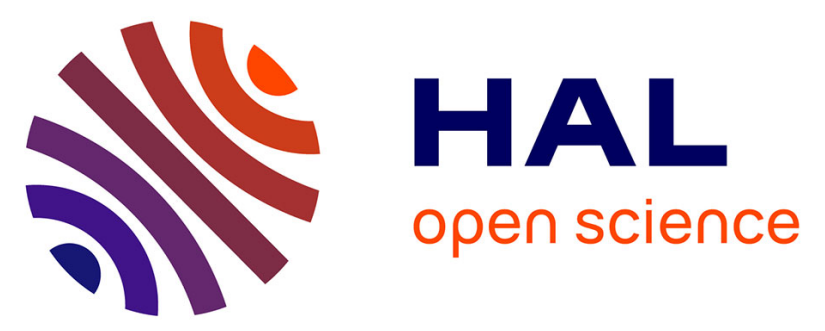

\title{
Importance of dosimetry protocol for cell irradiation on a low X-rays facility and consequences for the biological response
}

Morgane dos Santos, Vincent Paget, Mariam Ben Kacem, Francois Trompier, Mohamedamine Benadjaoud, Agnes Francois, Olivier Guipaud, Marc

Benderitter, Fabien Milliat

\section{To cite this version:}

Morgane dos Santos, Vincent Paget, Mariam Ben Kacem, Francois Trompier, Mohamedamine Benadjaoud, et al.. Importance of dosimetry protocol for cell irradiation on a low X-rays facility and consequences for the biological response. International Journal of Radiation Biology, 2018, 94 (6), pp.597-606. 10.1080/09553002.2018.1466205 . hal-02457228

\section{HAL Id: hal-02457228 \\ https://hal.science/hal-02457228}

Submitted on 15 Mar 2021

HAL is a multi-disciplinary open access archive for the deposit and dissemination of scientific research documents, whether they are published or not. The documents may come from teaching and research institutions in France or abroad, or from public or private research centers.
L'archive ouverte pluridisciplinaire HAL, est destinée au dépôt et à la diffusion de documents scientifiques de niveau recherche, publiés ou non, émanant des établissements d'enseignement et de recherche français ou étrangers, des laboratoires publics ou privés. 


\section{Importance of dosimetry protocol for cell irradiation on a low X-rays facility and consequences for the biological response}

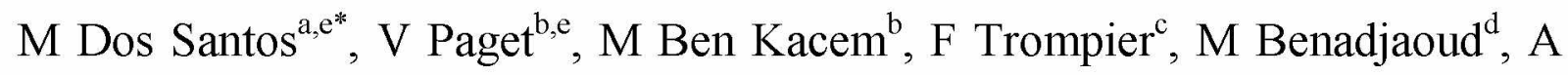
François $^{\mathrm{b}}$, O Guipaud ${ }^{\mathrm{b}}, \mathrm{M}^{\mathrm{B}}$ Benderitter ${ }^{\mathrm{d}}$ and $\mathrm{F}_{\text {Milliat }}{ }^{\mathrm{b}}$

anstitute for Radiological Protection and Nuclear Safety (IRSN), Department of RAdiobiology and regenerative MEDicine (SERAMED), Laboratory of Radiobiology of Accidental exposures (LRAcc) Fontenay-aux-Roses, France; ${ }^{b}$ Institute for Radiological Protection and Nuclear Safety (IRSN), Department of RAdiobiology and regenerative MEDicine (SERAMED), Laboratory of MEDical Radiobiology (LRMed), Fontenay-auxRoses, 92260, France; 'Institute for Radiological Protection and Nuclear Safety (IRSN), Department of DOSimetry, (SDOS), Ionizing Radiation Dosimetry Laboratory (LDRI), Fontenay-aux-Roses, 92260, France; Institute for Radiological Protection and Nuclear Safety (IRSN), Department of RAdiobiology and regenerative MEDicine (SERAMED), Fontenay-aux-Roses, France.

${ }^{e}$ Equally contributed to this work

*Corresponding author: morgane.dossantos@irsn.fr 


\section{Importance of dosimetry protocol for cell irradiation on a low X-rays facility and consequences for the biological response}

Purpose: The main objective of radiobiology is to establish links between doses and radiation-induced biological effects. In this context, well-defined dosimetry protocols are crucial to the determination of experimental protocols. This work proposes a new dosimetry protocol for cell irradiation in a SARRP and shows the importance of the modification of some parameters defined in dosimetry protocol for physical dose and biological outcomes.

Materials and methods: Once all parameters of the configuration were defined, dosimetry measurements with ionization chambers and EBT3 films were performed to evaluate the dose rate and the attenuation due to the cell culture medium. To evaluate the influence of changes in cell culture volume and/or additional filtration, 6-well plates containing EBT3 films with water were used to determine the impact on the physical dose at $80 \mathrm{kV}$. Then, experiments with the same irradiation conditions were performed by replacing EBT3 films by HUVECs. The biological response was assessed using clonogenic assay.

Results: Using a $0.15 \mathrm{~mm}$ copper filter lead to a variation of $+1 \%$ using medium thickness of $0.104 \mathrm{~cm}$ to $-8 \%$ using a medium thickness of $0.936 \mathrm{~cm}$ on the physical dose compare to the reference condition $(0.313 \mathrm{~cm})$. For the $1 \mathrm{~mm}$ aluminum filter, a variation of $+8 \%$ to $-40 \%$ for the same medium thickness conditions has been observed. Cells irradiated in the same conditions showed significant differences in survival fraction, corroborating the effects of dosimetric changes on physical dose.

Conclusion: This work shows the importance of dosimetry in radiobiology studies and the need of an accurate description of the dosimetry protocol used for irradiation.

Keywords: dosimetry, low-energy X-rays, SARRP, clonogenic assay, HUVECs

\section{Introduction}

During the last three decades, the importance of dosimetry in radiobiology studies and the standardization and harmonization of dosimetry formalism have been highlighted (Zoetelief et al., 1985; Zoetelief and Jansen, 1997; Zoetelief et al., 2001; Coleman et al., 2003; Desrosiers et al., 2013; Trompier et al., 2016). As radiobiology aims to establish a relationship between delivered doses and biological effects, dosimetry is an essential part of experimental designs. 
Different dosimetry protocols have been established to define a reference dose-rate in low energy X-rays facilities. At least six different protocols can be used to establish a reference dose-rate ((DIN), 1988; (DIN), 1996; (NCS), 1997; IAEA, 2000; Ma et al., 2001). The difference in terms of reference dose rate values between these protocols can reach $7 \%$ according to Peixoto and Andreo (Peixoto and Andreo, 2000), depending on the dosimetric approach (air kerma versus dose to water). Moreover, the reference dose-rate, because evaluated in air or in a water equivalent phantom, does not always allow estimating accurately the real dose delivered to the biological system considered. The non-representativeness of the reference dose-rate has been specially highlighted in the past for small animal irradiations (Zoetelief and Jansen, 1997; Peixoto and Andreo, 2000; Zoetelief et al., 2001; Yoshizumi et al., 2011; Noblet et al., 2014; Pedersen et al., 2016), even if nowadays Treatment Planning System coupled with imaging system allow overcoming this difficulty for most of irradiation configurations. However, cell-culture irradiation was never identified as being possibly problematic regarding the representativeness of the reference dose rate. In this paper, we show that even for cell-culture irradiation, the use of the established protocols of dosimetry do not always allow estimating the real dose delivered to the cells and that the dose difference is sufficient to generate observable biological difference. For example, difference in set-up as volume of cell-culture media or in the type of container may generate significant dose differences, especially for voltage below $100 \mathrm{kV}$. Thus, we propose a new protocol for dosimetry that takes into account the influence of the set-up and allows estimating accurately and reproductively the real dose delivered to cell.

The aim of the present work was to define a new dosimetry protocol for cell irradiation in a low X-ray irradiation facility in order to have robust and reproducible protocols and to be able to compare and interpret experiments. With existing dosimetry protocols reference dose rate are determined free in air on in a water phantom depending on the selected protocol. But 
with low X-ray energy, a second step is necessary to take into account the influence of the irradiation set-up (container, cell culture volume, number of containers...), to estimate the real dose delivered to cells. We demonstrate in this paper, that the difference, in terms of dose rate between the actual dose rate to the cells and the reference dose-rate is not always negligible, especially for light additional filtrations. At IRSN, a dedicated dosimetry is performed for each set-up, even for identical beam conditions. Moreover, to highlight the importance of maintaining identical conditions of irradiations (as cell culture volume for example), we assessed the impact of manual errors/protocol changes in terms of biological effects on cell populations. To show this, cells were irradiated at $80 \mathrm{kV}$ with different cell culture volume and/or filtrations (aluminum or copper) and the impact of these parameters on the surviving cell fraction was experimentally verified using the clonogenic assay.

\section{Material and methods}

\section{X-rays irradiation facility}

All irradiations described in this paper were performed at the Small Animal Radiation Research Platform (SARRP) from XSTRAHL (XSTRAHL Ltd., UK) at IRSN (Fontenayaux-Roses, France). SARRP is an image guided micro irradiator composed of a Varian X-ray tube (NDI-225-22) attached to a gantry that can be rotated between -180 and 180 degrees (Deng et al., 2007; Wong et al., 2008). The X-ray tube specifications are an inherent filtration of $0.8 \mathrm{~mm}$ of Beryllium, a large focal spot size about $3 \mathrm{~mm}$, a high voltage (HV) range about 30 to $225 \mathrm{kV}$ and a maximum current of the machine can reach $30 \mathrm{~mA}$ (depending on the $\mathrm{HV}$ applied). This device has been originally designed for small animal irradiation, but it could be also used for other applications, such as cell irradiations, even if its limited beam size is not optimum for that type of application. The irradiation field is limited to roughly 20 by $20 \mathrm{~cm}^{2}$ at the isocenter (Source detector distance about $35 \mathrm{~cm}$ ) including the penumbra region (see 
section Homogeneity of irradiation field). At IRSN, the SARRP is also used in routine for irradiation of cell culture at doses at HV below $100 \mathrm{kV}$. In this work, cells were irradiated at doses ranging from 0 to $4 \mathrm{~Gy}$ at $80 \mathrm{kV}$ and at a dose-rate of $0.63 \mathrm{~Gy} \cdot \mathrm{min}^{-1}$ in terms of air kerma (using copper or aluminum additional filtration, named configurations 1 and 2 , respectively).

\section{Protocols used for implementation of dosimetry on SARRP}

In implementing dosimetry protocols on SARRP at IRSN and in ensuring the reproducibility of irradiation conditions from one experiment to another, some parameters have to be fixed for each case. These parameters are: HV of the X-rays tube $(30-220 \mathrm{kV})$, additional filtration $(0.15 \mathrm{~mm}$ copper or $1 \mathrm{~mm}$ aluminum), detectors used, source-sample distance, field size, shape and geometry, dosimetry method/protocol, dose quantity $\left(\mathrm{K}_{\mathrm{air}}, \mathrm{K}_{\text {water, }} \mathrm{D}_{\text {water }}\right)$, cell containers, type and volume of medium and uncertainties.

The dosimetry protocol was carried out in two steps as illustrated in the schema reported in figure 1 . The first step consisted of the measurement of absolute dosimetry with an ionization chamber, calibrated in air kerma free-in-air conditions. As the quantity of cell culture medium was small in the containers, we chose to perform the measurements of absolute dosimetry not on a phantom but on the different cell culture supports used for biological experiments, as illustrated in figure 1 in terms of air kerma. To avoid the effect of the attenuation due to the base of microplate, a little square having the dimension of the detection surface of the ionization chamber was removed within the center of the well. The measured air kerma ( $\mathrm{K}_{\text {air }}$ ) was converted to water kerma free in air, using the ratio of mean mass energy transfer coefficients for water to air, with respect to the photon fluence spectrum considered. Thanks to these measurements, we were able to determine the dose rate for each irradiation configurations and determine the time needed to administer a certain dose. 
Then, the second step consists in the quantification of the attenuation due to cell culture medium. For this, EBT3 radiochromic films were placed inside cell container and irradiation with and without the exact quantity of the cell culture medium for each configuration were performed. For this, small pieces of radiochromic film were placed inside the support used for cell irradiation: T25, T75, 6- to 24-well plates, Nunc ${ }^{\mathrm{TM}}$ Lab-Tek $^{\mathrm{TM}}$ Chamber Slide System. At least three pieces of radiochromic films were irradiated for each condition. Finally, the radiochromic films were analyzed by the method described in the section called Relative dosimetry with radiochromic films. From these results, attenuation of the cell culture medium was taken into account in calculating dosimetry.

\section{Absolute dosimetry with ionization chamber}

Absolute dosimetry was performed by using a calibrated ionization chamber, which confers various advantages, especially high precision, accuracy, and reproducibility. Two types of ionization chamber were used in this work: the semiflex 31002 and the soft X-ray 23342. The semiflex ionization chamber 31002 is cylindrical with a cavity volume of $0.125 \mathrm{~cm}^{3}$ calibrated here in the range of 100-300 kV X-rays. The second ionization chamber was a TM 23342 plane parallel chamber with a cavity volume of $0.02 \mathrm{~cm}^{3}$ calibrated here in the range of $30-100 \mathrm{kV}$. These two ionization chambers were calibrated in air kerma free in air at the IRSN reference facility FP-15-142 for the soft X-ray 23342 (H30, H60 and H100 beams) and FP-15-126 for the semiflex 31002 (H60, H100 and H200 beams). The characteristics of these X-ray beams are given in ISO standard 4037-1 ((ISO), 1996). For measurements, the two ionization chambers were connected to a UNIDOS ${ }^{\text {webline }}$ Universal Dosemeter / Electrometer and a high-voltage supply of 300 or $400 \mathrm{~V}$ depending on calibrations. 
The measurements were performed by following as closely as possible the recommendations compiled in the AAPM protocol for $40-300 \mathrm{kV}$ X-ray beam dosimetry in radiotherapy and radiobiology (Ma et al., 2001) and the TRS398 (IAEA, 2000).

Determination of the dose in air kerma free-in-air conditions is given by:

$$
K_{\text {air }}=M \times N_{\text {Kair }} \times K_{Q}
$$

Where:

$\mathbf{N}_{\text {Kair }}$ is the calibration factor in terms of air kerma provided by the calibration laboratory.

$\mathbf{M}$ is the reading of the dosemeters corrected for temperature and pressure, polarity effect, ion recombination and electrometer calibration.

$\mathbf{K}_{\mathbf{Q}}$ is the correction factor for the radiation quality $\mathbf{Q}$ depending on the beam quality specification.

Concerning determination of the beam quality specification, so of the $\mathrm{Kq}$ factor, it has long been known that the usual quantities are the kilovoltage $(\mathrm{kV})$ generating potential and the half-value layer (HVL) determined in copper or aluminum (mm) (IAEA, 2000). For each HV used with our SARRP, the corresponding HVL value was measured by following as closely as possible the method described in section II.B of the AAPM protocol (Ma et al., 2001). As the distance of 1 meter between the irradiation source and the detector cannot be achieved with the SARRP, we chose a distance of $70 \mathrm{~cm}$ for the measurements, thanks to which we are able to determine with accuracy the calibrated factor for each HT and filtration used on the SARRP. Calibration factors of each ionization chambers were also measured following the AAPM protocol.

Uncertainty in the ionization chamber measurements is mainly related to the calibration factor, which ranged between 1.64 and $2.10 \%$ at a $66 \%$ confidence level $(2.7-4.4 \%$ at a $95 \%$ confidence level), depending on the ionization chamber used and calibration. Other sources of 
uncertainty were: measurements (from 0.01 to $0.1 \%$ ), warm-up effect and the correction factors $\mathrm{k}_{\mathrm{pol}}, \mathrm{k}_{\mathrm{elec}}, \mathrm{k}_{\mathrm{T}, \mathrm{P}}$ (from 0.01 to $0.1 \%$ ). The maximum overall uncertainty ranged from 2.8 to $4.5 \%$ at a $95 \%$ confidence level. To incorporate other possible sources of uncertainty, a conservative value from 3 to $5 \%$ was considered $(k=2)$.

The measured air kerma $\left(\mathrm{K}_{\text {air }}\right)$ was converted to water kerma, free in air, using the ratio of mean mass energy transfer coefficients for water to air, evaluated over the photon fluence spectrum free in air calculated with SpekCalc software (Poludniowski et al., 2009), in the absence of a phantom. This coefficient was calculated for each configuration from the energy spectrum and the NIST table (Hubbell and Seltzer, 2004).

$$
K_{\text {water }}=K_{\text {air }} \times\left[\left(\frac{\bar{\mu}_{t r}}{\rho}\right)_{\text {air }}^{w}\right]_{\text {air }}
$$

\section{Relative dosimetry with radiochromic films}

To quantify the attenuation due to cell culture medium, relative dose measurements were performed with EBT3 self-developing Gafchromic® film (Ashland ISP Advanced Materials, NJ, USA) composed of an active radiochromic layer $28 \mu \mathrm{m}$ thick laminated between two polyester layers $125 \mu \mathrm{m}$ thick (Devic et al., 2005). EBT3 films were scanned in a 48 bit redgreen-blue TIFF format using an Epson Perfection V700 scanner at 150 dpi in transmission mode with no image correction. For each scan, the films were placed at the same position at the center of the bed scanned and in the same orientation. Pieces of film were cut at least 24 hours before irradiation in order to allow mechanically created disturbances to relax and were read at least 24 hours after irradiation. Images were converted to optical density (OD) and then to doses using a homemade $\mathrm{C}$ program using the red channel method (Devic et al., 2005; Micke et al., 2011). EBT3 films were calibrated between 0 and 5 Gy by steps of 0.5 Gy, and the points of the calibration curve were fitted with a $4^{\text {th }}$ degree polynomial curve. 
Uncertainties in film dose measurements were evaluated and the main contribution to the overall uncertainty was due to the absolute dose measurement with the ionization chamber and ranged from 2.1 to $3.5 \%$ at a $95 \%$ confidence level, depending on the ionization chambers and calibration. The other sources of uncertainties were: warm-up effect and reproducibility of the scanner (around $0.05 \%$ after at least 25 pre-scans), measurement of the film optical density (around $0.5 \%$ ) and film calibration (around 1.5\%). The maximum overall uncertainty was $3.81 \%$ at a $95 \%$ confidence level. To incorporate other possible sources of uncertainty, a conservative value of $4 \%$ was considered $(k=2)$.

\section{Cell culture}

Human umbilical vein endothelial cells (HUVECs, C2519A) from Lonza were cultured in EGM-2 MV culture medium (Lonza) according to the manufacturer's instructions and placed in an incubator at $37^{\circ} \mathrm{C}$ with $5 \% \mathrm{CO}_{2}$ and $95 \%$ humidity. For all the experiments, HUVECs at passage 2 were routinely seeded in 6-well microplates 3 hours before irradiation. This interval before irradiation was previously determined to be sufficient to allow cell adhesion and at the same time to avoid a restart in proliferation i.e. avoiding cell division just before irradiation (Abderrahmani et al., 2012).

\section{Clonogenic assays}

The radiosensitivity of HUVECs was assessed by clonogenic assay (Franken et al., 2006). Briefly, cells were seeded in 6-well culture plates (1000 cells/well for doses from 0 to $1 \mathrm{~Gy}$ and 2000 cells/well for doses from 2 to $4 \mathrm{~Gy}$ ) and, three hours after plating (adhesion step), microplates containing adherent HUVECs were irradiated at different doses ( 0 (control), 0.5 , $1,2,3,4,5$ and $6 \mathrm{~Gy}$ ) on the SARRP at $80 \mathrm{kV}$ and $0.63 \mathrm{~Gy} \cdot \mathrm{min}^{-1}$ (using additional copper or aluminum filtration, named configurations 1 and 2, respectively). Nine days after irradiation, cells were fixed for 15 min with $4 \%$ final (v/v) paraformaldehyde (in PBS without $\mathrm{Ca}^{2+}$ and 
$\mathrm{Mg}^{2+}$ ) and then stained for 30 minutes with Giemsa (Sigma Aldrich) at a final concentration of $10 \%(\mathrm{v} / \mathrm{v})$ (in milliQ water). Colonies containing more than 60 cells (corresponding to at least 6 doubling times) (Franken et al., 2006) were counted using an automatic counting "colony counter pen" while clone size was checked under microscope.

\section{Statistical analysis}

The number of scored colonies $y_{i}(d)$ at each dose $d$ and plate $i$ was modeled using the following binomial distribution:

$$
y_{i}(d) \sim \mathfrak{B}\left(N_{i}(d), S(d)\right)
$$

Where $N_{i}(d)$ is the number of seeded cells and $S(d)$ the "success" probability for a cell to grow into a colony.

More precisely, the survival fraction $\mathrm{S}(\mathrm{d})$ is modeled according to the linear quadratic model:

$$
S(d)=\exp \left(-c-\alpha d-\beta d^{2}\right)=P E \times \exp \left(-\alpha d-\beta d^{2}\right)
$$

Or equivalently in a log scale:

$$
\log (S(d))=-c-\alpha d-\beta d^{2}=\log (P E)-\alpha d-\beta d^{2}
$$

Where $c, \alpha$ and $\beta$ are the model parameters and $P E=S(0)=\exp (-c)$ represents the plating efficiency, i.e. the surviving fraction of unirradiated cells. This Bernoulli trials representation was recently shown to be suitable for modeling clonogenic survival data (Shuryak et al., 2016).

According to filtrations and volumes, the survival fractions among two experimental groups $G_{0}$ (reference) and $G_{1}$ were compared using a likelihood ratio test (LRT) for generalized linear models (here a binomial regression). With the same notations as above, the idea is to test the hypothesis:

$$
H_{0}: S_{0}(d)=S_{1}(d) \text { for all doses d }
$$


against its alternative:

$$
H_{1}: S_{0}(d) \neq S_{1}(d) \text { for some dose d. }
$$

In the pooled $G_{0}$ and $G_{1}$ data and under $H_{0}$, the parameters in model (1) are estimated in a "free-group" way:

$$
\log \left(S^{H_{0}}(d)\right)=-c_{0}-\alpha_{0} d-\beta_{0} d^{2}
$$

In the pooled $G_{0}$ and $G_{1}$ data and under $H_{1}$, the radiation-related parameters $\alpha$ and $\beta$ can be different in the two groups, and this can be formulated by introducing an "interaction" covariate $\chi_{I}$ equal to 0 in group 0 and 1 in group 1 :

$$
\begin{aligned}
\log \left(S^{H_{1}}(d)\right)= & -c_{0}-\left(\alpha_{0}+\alpha_{I} \chi_{I}\right) d-\left(\beta_{0}+\beta_{I} \chi_{I}\right) d^{2} \\
& =-c_{0}-\alpha_{0} d-\alpha_{I} \chi_{I} d-\beta_{0} d^{2}-\beta_{I} \chi_{I} d^{2}
\end{aligned}
$$

Where $c_{0}, \alpha_{0}$ and $\beta_{0}$ are the reference group parameters and $\alpha_{I}, \beta_{I}$ are interaction parameters. We reject $\mathrm{H}_{0}$ in favor of $\mathrm{H}_{1}$ for large values of the LRT-statistic

$$
T=-2\left(L L_{H_{0}}-L L_{H_{1}}\right)
$$

Where LL denotes the logarithm of binomial regression likelihood:

$$
L L=\sum_{d} \sum_{i}\left[y_{i}(d) \log (S(d))+\left(N_{i}(d)-y_{i}(d)\right) \log (1-S(d))\right]
$$

The null distribution (under $\mathrm{H}_{0}$ ) of the test statistics $\mathrm{T}$ is approximated using a permutation method (Good, 2005; Pesarin and Salmaso, 2010) where a permutation sample is generated by randomly partitioning the clonogenic survival data within each dose into groups of the same size as $\mathrm{G} 0$ and $\mathrm{G} 1$.

Computations for this study were carried out using MATLAB Software, version 8.2.0.701 (Mathworks R2013b). 


\section{Results}

\section{Dosimetry measurements on the SARRP irradiator}

Measurements of beam quality index: $H V L$

For the measurements of beam quality index, the procedure described in the AAPM protocol (Ma et al., 2001) was followed. Nevertheless, as the distance between the irradiation source and the floor of the irradiator is limited, it was not possible to achieve a distance of 1 meter between the source and the ionization chamber as recommended (Ma et al., 2001). Due to this limitation, we chose a detector-source distance of $70 \mathrm{~cm}$. HVL value were measured for $\mathrm{HV}$ between 40 and $220 \mathrm{kV}$ for the two additional filtrations available on the SARRP (supplementary data II). On the following of this work, where irradiations were performed at $80 \mathrm{kV}, \mathrm{HVL}$ values about 0.056 and $0.138 \mathrm{~mm}$ of copper were measured for $1 \mathrm{~mm}$ or 0.15 $\mathrm{mm}$ of Aluminum or Copper additional filtrations respectively.

\section{Homogeneity of irradiation field}

As the SARRP irradiator is mainly used for small animal irradiation with very small irradiation fields (less than $10 \times 10 \mathrm{~mm}^{2}$ ), the irradiation field at the reference position (source-sample distance $35 \mathrm{~cm}$ ) in open field conditions, is limited to roughly $20 \times 20 \mathrm{~cm}^{2}$ including penumbra regions and roughly $12 \times 12 \mathrm{~cm}^{2}$ without penumbra regions, and by taking into account margins to avoid errors induced by plate positioning. In order to have the same dose in all our cells, we decided to limit the efficient irradiation field at the central region materialized by black lines in figure 2 .

One way to increase the irradiation field is to increase the source-sample distance, but because of dose rate limitations for some configurations, we had to irradiate at the reference position. For small containers like Nunc ${ }^{\mathrm{TM}} \mathrm{Lab}^{-\mathrm{Tek}^{\mathrm{TM}}}$ or $\mathrm{T} 25$, the irradiation field is much 
larger than the cell culture support. Nevertheless, for 6-, 12-, 24- or 96-well plates, it is not possible to irradiate the whole cell culture support at the same dose as the dimensions of the plate are about $12.7 \times 8.5 \mathrm{~cm}^{2}$. Thus, in order to deliver the same dose to all cells, we removed columns that were not completely covered by the irradiation field, as illustrated in figure 3 for the 6-plate well. The wells outside our irradiation field were filled with water to maintain humidity and scattered radiation compare with fully irradiated plates. Thanks to these considerations, we are able to irradiate cells at $98 \%$ isodose. The same procedure was followed for the 12-, 24- and 96-well plates.

\section{Dose rate measurement}

As previously mentioned, absolute dose rate measurements were performed with two ionization chambers. The specificity of our protocol is that air kerma dose rate is measured in each experiment in the container used for cell irradiation in order to take into account the container effect. In order to determine the dose rate on cells, this value is converted into water kerma using the ratio of mean mass energy transfer coefficients for water to air for the energy spectrum considered and by also taking into account the attenuation of the cell culture medium. On the following of this work, for irradiations at $80 \mathrm{kV}$, dose rate was measured in six well plate, where lids were replaced by sterile films (Breathe-EASIER ${ }^{\mathrm{TM}}$ Diversified Biotech, ref BERM-2000), with the TM23342 ionization chamber at the isocenter (source-sample distance $=35 \mathrm{~cm}$ ). The dose rate obtained is $0.63 \mathrm{~Gy} / \mathrm{min}$ in air kerma. In order to have the same dose rate for each filtration, the current of the SARRP platform was $6.8 \mathrm{~mA}$ for the 1 $\mathrm{mm}$ aluminum filtration and $20.7 \mathrm{~mA}$ for the $0.15 \mathrm{~mm}$ copper filtration.

Here we propose a protocol that differs somewhat from the reference dosimetry protocol. We performed dosimetry measurements under conditions as close as those of irradiations in order to take into account all parameters that may influence the physical dose to 
cells, especially at low X-ray energy, like material of containers or the quantity of cell culture medium. Measurements free in air without the container were also performed to evaluate its influence. As an example in relation with results presented after, at $80 \mathrm{kV}$ with copper filtration, the presence of the container increases the dose rate by $4.3 \%$. Therefore, for this type of configuration, the representativeness of a free in air measurements could be questioned.

\section{Influence of the variation of parameters on the physical dose}

To highlight the importance of accurate dosimetry protocols and irradiation conditions, two experiments at $80 \mathrm{kV}$ were performed with the two additional filtrations available with the SARRP $(0.15 \mathrm{~mm}$ copper and $1 \mathrm{~mm}$ aluminum), and by varying the quantity of media on the container. All our results are compared to our reference irradiation condition which is a 6-well microplate filled with $3 \mathrm{~mL}$ of cell culture medium, thus taking into account the attenuation due to the cell culture medium.

In both cases, dosimetry was performed using ionization chamber TM23342 and radiochromic EBT3 films. Twelve pieces of radiochromic film were irradiated with $3 \mathrm{~mL}$, $9 \mathrm{~mL}$ and $1 \mathrm{~mL}$ per well corresponding respectively to $0.313,0.936$ and $0.104 \mathrm{~cm}$ of thickness. As our reference condition is $3 \mathrm{~mL}$ per well, all well plates were irradiated for the same time, corresponding to a dose of $2 \mathrm{~Gy}$ received by the cell for the reference configuration. These films were analyzed by following the method explained in section Relative dosimetry with radiochromic films and the results are reported in Table 1.

As expected, these results show that dose increases when medium volume decreases. These variations with respect to the reference configuration were greater in the case of aluminum filtration due to a higher proportion of very low-energy $\mathrm{X}$-rays. If we compare the energy spectrum obtained with the two additional filtrations, a greater proportion of very low- 
energy X-rays pass through the aluminum filtration (figure 4). These very low-energy X-rays are quickly attenuated and stopped in the media, so as the quantity of media increases, less Xray energy reaches the radiochromic films, leading to dose diminution. For a given dose rate determined with a reference protocol (AAPM, IAEA,..), the dose really delivered to cells can significantly varied depending of the cell container and the volume of cell culture medium use by the experimenter. These data questioned again the representatives of reference measurements performed free in air. Therefore, especially for the irradiation with HV below $100 \mathrm{kV}$, we have implemented a protocol to take into account the influence of the container and of the cell culture medium to provide a reference dose closer to the dose received by cells.

\section{Influence on the biological response measured by the clonogenic assay}

Clonogenic assay was used to evaluate changes in the set-up parameters in cell-irradiation configuration (filtration and/or volume of cell culture medium). HUVECs were irradiated from 0 to $4 \mathrm{~Gy}$ at $80 \mathrm{kV}$ and $0.63 \mathrm{~Gy} \cdot \mathrm{min}^{-1}$ (using copper or aluminum additional filtration, named configurations 1 and 2, respectively). Cell survival fractions were calculated for each dose of irradiation. The two reference conditions $(3 \mathrm{~mL} /$ well in configurations 1 and 2$)$ are depicted by green curves (Panels A and B, figure 5). Strictly similar experiments were conducted with 1 or $9 \mathrm{~mL} /$ well for configurations 1 and 2 (Panels $\mathrm{A}$ and $\mathrm{B}$, figure 5, respectively). These modified volumes ( 1 and $9 \mathrm{~mL}$ ) were used only during the irradiation step. Indeed each well contains $3 \mathrm{~mL}$ during the three hours adhesion step prior irradiation. Just before irradiation step, $2 \mathrm{~mL}$ were removed on wells wich will contain $1 \mathrm{~mL}$, and $6 \mathrm{~mL}$ were added into wells which will contain $9 \mathrm{~mL}$. Then, just after irradiation step, $2 \mathrm{~mL}$ were added on wells containing $1 \mathrm{~mL}$, and $6 \mathrm{~mL}$ were removed from wells containing $9 \mathrm{~mL}$. Thus, during the next 9 days, each condition is performed with the same amount of medium per well. 
We observed that only the $9 \mathrm{~mL}$ condition significantly impacted the survival fraction curve in configuration $1(\mathrm{P}<0.001)$ (figure 5. Panel A). The $1 \mathrm{~mL}$ condition (red dotted curve, Panel A, figure 5) was still significantly different $(\mathrm{P}=0.03)$ from the reference condition (green curve, Panel A, figure 5) at the highest doses, in the neighborhood of 4 Gy. On the other hand, in configuration 2 , the survival curves for 1 and $9 \mathrm{~mL}$ were significantly different from the reference condition $(\mathrm{P}<0.001$ both) (figure 5 Panel $\mathrm{B}$ ). These observations are in accordance regarding the dose variations measured on EBT3 radiochromic films (refer to Table 1) for two conditions of irradiation (configurations 1 and 2)

Based on these measured variations compared to the reference condition, we corrected the "wrong dose" to the "right deposited dose" by taking into account the attenuation of the cell culture medium to visualize more easily the impact of such variations (figure 6), where the green curve represents the reference condition, the red curve represents the biological response measured with the "wrong dose" and the blue curve represents the same data as the red curve but after correction of the abscissa (dose) with the "right deposited dose" values according to the results in Table 1.

We observed that compared to the reference condition $(3 \mathrm{~mL} /$ well), volume errors in configuration 2 strongly impact the survival fraction curves (Panels $\mathrm{C}$ and D in figure 5), decreasing the survival fraction for $1 \mathrm{~mL} /$ well (Panel C, figure 5) and increasing the survival fraction in the case of $9 \mathrm{~mL} /$ well (Panel D, figure 5). Finally, we also observed an atypical curve for the $9 \mathrm{~mL}$ condition in configuration 2 (Panel $\mathrm{D}$, figure 5). In this condition, the survival curve has a negative $\beta$ factor instead of being positive and fitting an LQ-model (red and blue curves, Panel D, Figure 5). An example of clones obtained at 2 Gy for this particular condition ( $9 \mathrm{~mL} /$ well in configuration 2$)$ is depicted in Supplementary data III.

\section{Discussion}


This work was initiated in the framework of the implementation of dosimetry protocols for cell irradiation on the SARRP platform. With the development and democratization of the use of cost-effective equipment like small X-ray irradiators, which are easy to use, self-protected and have fewer radioprotection constraints than cesium or cobalt sources, adapted dosimetry protocols are needed. Several studies have highlighted the importance of the description and formalism of dosimetry protocols, and well-defined dosimetry protocols, especially at lowenergy, appear to be crucial in establishing links between doses and radiation-induced biological effects (Zoetelief et al., 2001; Desrosiers et al., 2013; Trompier et al., 2016). Nevertheless, although some protocols have already been described in the literature for this type of irradiation (Zoetelief et al., 1985; Desrosiers et al., 2013), where dosimetry measurements are performed with ionization chambers and calibrated in dose to water or in air kerma, at the surface of a solid water phantom or free in air, we implemented a new protocol in order to perform dosimetry measurements as close as possible to real cell irradiation conditions. For this, measurements were made of absolute dosimetry with an ionization chamber and relative dosimetry with EBT3 radiochromic films in each cell container, to evaluate dose rate and attenuation due to the cell culture medium. Especially with low-energy X-rays, the quantity of cell culture medium (attenuation), containers and the use of a phantom (quantity of secondary electrons created) can influence the physical dose (Noblet et al., 2014).

To highlight the importance of all parameters of a dosimetry protocol, we evaluated the impact of change in the quantity of cell culture medium on the physical dose at $80 \mathrm{kV}$ for aluminum and copper filtration. Change in volume and/or filtration led to significant variations in the physical doses measured by EBT3 films, which illustrates the importance of rigorous adhesion to the protocol to avoid introducing errors in the dose delivered to cells. To verify the possible effects on the biological response, we measured the survival fraction of 
HUVECs using the clonogenic assay. HUVECs were chosen as a biological model due to their capability to form clones in dishes (Abderrahmani et al., 2012). Moreover we currently use these cells as biological model to evaluate the effects of ionizing radiations since many years in several of our research project, vascular injury being one of the most common effects of radiotherapy on normal tissues (Corre et al., 2013; Korpela and Liu, 2014). The clonogenic assay was chosen since the evaluation of radiosensitivity is historically linked to the survival fraction measured by the clonogenic assay, which is the gold standard in such evaluations (Puck and Marcus, 1956). This assay is based on the ability of a single cell to grow into a colony after a stress (Munshi et al., 2005; Franken et al., 2006; Rafehi et al., 2011). The representation of the survival fraction as a function of the dose leads to survival curves, which are modeled by the linear-quadratic model (LQ-model) (Chadwick and Leenhouts, 1981). Based on this approach, we used the LQ-model to fit our cell survival curves in each set of irradiation conditions (figure 5). The results indicate that, the survival fractions for cells exposed to X-ray at $80 \mathrm{kV}$ for $1 \mathrm{~mm}$ aluminum filtration is higher than for the $0.15 \mathrm{~mm}$ copper filtration at a same dose (figure 5c). Referring to the energy spectra of these two configurations of irradiation, we observed a shift of the energy spectrum towards low-energy X-rays for aluminum filtration, leading to a lower mean energy of the energy spectrum of about $37.8 \mathrm{keV}$ versus $47 \mathrm{keV}$ for copper filtration. This could explain why photons are more easily attenuated by the medium with aluminum filtration than with copper filtration, thus leading to more clones in aluminum filtration compared to cooper filtration (figure 5).

Filtration mistakes are possible as they are manually set up by the experimenter at SARRP, but this is not the only potential source of error when performing an experiment on such irradiator device. The volumes used in cell culture dishes vary greatly in the literature, but also handling errors in cell culture volumes can occur when performing the experiment. We therefore decided to change the volume for the two conditions of irradiation to 
demonstrate by proof of concept the importance of dosimetry formalism for cell irradiation on a SARRP platform and the effects on the biological response. The dose variation measurements performed with EBT3 films when the cell culture volume was changed were perfectly verified by clonogenic assay. Using additional copper filtration, when the reference volume $3 \mathrm{~mL} /$ well was replaced by 1 or $9 \mathrm{~mL} /$ well, EBT3 films indicated dose variations of $+1 \%$ and $-8 \%$, respectively. The clonogenic assay for $1 \mathrm{~mL} /$ well showed a significant difference ( $p=0.03$ ) mainly for the 4 Gy data, which could be partly explained by the higher distribution of the survival fraction values obtained at $4 \mathrm{~Gy}$ in the reference conditions. Moreover, we detected a significant difference for the $9 \mathrm{~mL} /$ well condition, the survival fraction being significantly greater $(p<0.001)$ than in the reference condition from 0 to $4 \mathrm{~Gy}$. These biological data fully corroborate the dosimetric measures of EBT3 films when considering the $9 \mathrm{~mL} /$ well condition. Concerning the configuration using additional aluminum filtration, the physical doses measured by EBT3 indicated an increase of around $8 \%$ when $3 \mathrm{~mL} /$ well was replaced by $1 \mathrm{~mL}$ of cell culture medium. These differences were confirmed at the biological level. Clonogenic assay performed with $1 \mathrm{~mL} /$ well led to a decrease of the survival fraction compared to the reference condition. Cells received a higher dose than expected, leading to the shift observed in the survival fraction curve. On the other hand, we obtained an atypical curve for the $9 \mathrm{~mL} /$ well condition (compared to the reference curve). Even though we observed a higher cell survival fraction, the linear quadratic part of the curve had a negative $\beta$ coefficient. A possible explanation is provided in Supplementary data III. According to the literature, the colony size cut-off is set to 60 cells per clone in our clonogenic assay experiments (Franken et al., 2006). When we carefully observed the wells in the 2 Gy condition, there were higher numbers of small clones (below 60 cells per clone) in the $9 \mathrm{~mL}$ condition than in the reference condition and even more than in the $1 \mathrm{~mL}$ condition. This could explain why the survival fraction at 2 Gy was lower than that expected for a more 
classic dose-response curve, fitting with the conventional LQ-model or at least a linear one. Indeed, $9 \mathrm{~mL}$ instead of the $3 \mathrm{~mL}$ per well leads to a lower dose received by the cells and possibly changing the adverse effects on exposed cells e.g. changing the nature of damages induced within cell population allowing more survey along the cell divisions even though these clones remain below the "size" cut-off at the end of the experiment. To verify this hypothesis, it should be interesting to characterize the phenotype of surviving cells within these "smaller clones" for both conditions $(1,3$ and $9 \mathrm{~mL})$. Finally, this observation is quite disturbing in terms of biological response. Moreover, it emphasizes the importance of correct and accurate physical/biological set-ups for irradiation in order to avoid inappropriate results and a lack of robustness and reproducibility of the data.

Our findings highlighted the importance of the dosimetry formalism for cell irradiations and show that a variation on setup parameters, like cell culture medium or cell container, is sufficient to induce observable biological difference, especially for experimentations performed with low X-rays facility. Aware of this problem, recommendations have been made to the experimenter to not change the cell container or the volume of cell culture medium in order to avoid incorrect dose delivered to cell. Obviously on SARRP facility, one could propose in order to limit the influence of volume cell culture media, the X-ray tube could be rotated by 180 degrees in order to irradiate the cell from below. This is not done at IRSN to avoid problem with the tube in case of leakage of flask and tube. Moreover, in a more general way, for classical X-rays cabinet dedicated to cell irradiation, irradiations are always performed from the top. Therefore, for this kind of facility, which is much more widely used than SARRP for cell irradiation, the recommendations proposed for the SARRP by IRSN are fully relevant.

\section{Conclusion}


Taken together, these results strongly support the fact that a dosimetry is needed for each irradiation set-up and that all the parameters defined for one set of irradiation conditions should be monitored to avoid errors in the dose delivered to the sample, e.g. do not change the volume of cell culture medium, and use the correct filtration. For low HV $(<100 \mathrm{kV})$, a single kerma-rate measurement in air in the center of the irradiation volume does not allow estimating the actual delivered dose to the biological target: each irradiation configuration necessitates a specific dosimetry. This present work highlights the importance of the dosimetry formalism and description for radiobiology studies to be able to compare and interpret experiments, particularly when important resources are put in place for interlaboratory comparison programs. Thus, a new formalism, applicable to many low X-rays facility, is proposed to take into account parameters influencing the delivered dose.

\section{Declaration of interest}

The authors report no conflict of interest. The authors alone are responsible for the content and writing of the paper.

\section{Grant support}

This work was supported by Electricité de France EDF (Groupe Gestion Projet Radioprotection) and the Institute for Radiological Protection and Nuclear Safety (ROSIRIS program) 


\section{Reference}

(DIN) DIfN 1988 Klinische Dosimetrie: Teil 4. Anwendung von Röntgenstrahlen mit Röhrenspannungen von 10 bis $100 \mathrm{kV}$ in der Strahlentherapie und in der Weichteildianostik DIN 6809DIN 6809

(DIN) DIfN 1996 Klinische Dosimetrie: Teil 5: Anwendung von Röntgenstrahlen mit Röhrenspannungen von 100 bis 400 kV in der Strahlentherapie DIN 6809-5DIN 6809-5

(ISO) IOfS $1996 \mathrm{X}$ and gamma reference radiation for calibrating dosemeters and doserate meters and for determining their response as a function of photon energy -- Part 1: Radiation characteristics and production methods ISO/TC 85/SC 2ISO/TC 85/SC 2

(NCS) NCvS 1997 Dosimetry of low and medium energy x-rays: A code of practice for use in radiotherapy and radiobiology Report No. 10

Abderrahmani R, Francois A, Buard V, Tarlet G, Blirando K, Hneino M, Vaurijoux A, Benderitter M, Sabourin JC and Milliat F 2012 PAI-1-dependent endothelial cell death determines severity of radiation-induced intestinal injury $P$ LoS One 7:e35740

Chadwick KH and Leenhouts HP 1981 The molecular theory of radiation biology / Springer-Verlag Berlin Heidelberg)

Coleman CN, Stone HB, Alexander GA, Barcellos-Hoff MH, Bedford JS, Bristow RG, Dynlacht JR, Fuks Z, Gorelic LS, Hill RP, Joiner MC, Liu FF, McBride WH, McKenna WG, Powell SN, Robbins ME, Rockwell S, Schiff PB, Shaw EG, Siemann DW, Travis EL, Wallner PE, Wong RS and Zeman EM 2003 Education and training for radiation scientists: radiation research program and American Society of Therapeutic Radiology and Oncology Workshop, Bethesda, Maryland, May 12-14, 2003 Radiat Res 160:729-37

Corre I, Guillonneau M and Paris F 2013 Membrane signaling induced by high doses of ionizing radiation in the endothelial compartment. Relevance in radiation toxicity Int $J \mathrm{Mol} S \mathrm{Ci}$ $14: 22678-96$

Deng $\mathrm{H}$, Kennedy CW, Armour E, Tryggestad E, Ford E, McNutt T, Jiang L and Wong J 2007 The smallanimal radiation research platform (SARRP): dosimetry of a focused lens system Phys Med Biol 52:2729-40

Desrosiers M, DeWerd L, Deye J, Lindsay P, Murphy MK, Mitch M, Macchiarini F, Stojadinovic S and Stone H 2013 The Importance of Dosimetry Standardization in Radiobiology J Res Nat/ Inst Stand Technol 118:403-18

Devic S, Seuntjens J, Sham E, Podgorsak EB, Schmidtlein CR, Kirov AS and Soares CG 2005 Precise radiochromic film dosimetry using a flat-bed document scanner Med Phys 32:2245-53

Franken NA, Rodermond HM, Stap J, Haveman J and van Bree C 2006 Clonogenic assay of cells in vitro Nat Protoc 1:2315-9

Good PI 2005 Permutation, Parametric, and Bootstrap Tests of Hypotheses: Springer New York)

Hubbell JH and Seltzer SM 2004 Tables of X-Ray Mass Attenuation Coefficients and Mass EnergyAbsorption Coefficients (version 1.4)

IAEA 2000 Absorbed Dose Determination in External Beam Radiotherapy (Vienna: INTERNATIONAL ATOMIC ENERGY AGENCY)

Korpela E and Liu SK 2014 Endothelial perturbations and therapeutic strategies in normal tissue radiation damage Radiat Oncol 9:266

Ma CM, Coffey CW, DeWerd LA, Liu C, Nath R, Seltzer SM and Seuntjens JP 2001 AAPM protocol for 40-300 kV x-ray beam dosimetry in radiotherapy and radiobiology Med Phys 28:868-93

Micke A, Lewis DF and Yu X 2011 Multichannel film dosimetry with nonuniformity correction Med Phys 38:2523-34

Munshi A, Hobbs M and Meyn RE 2005 Clonogenic cell survival assay Methods Mol Med 110:21-8

Noblet C, Chiavassa S, Paris F, Supiot S, Lisbona A and Delpon G 2014 Underestimation of dose delivery in preclinical irradiation due to scattering conditions Phys Med 30:63-8

Pedersen KH, Kunugi KA, Hammer CG, Culberson WS and DeWerd LA 2016 Radiation Biology Irradiator Dose Verification Survey Radiat Res 185:163-8 
Peixoto JG and Andreo P 2000 Determination of absorbed dose to water in reference conditions for radiotherapy kilovoltage $x$-rays between 10 and $300 \mathrm{kV}$ : a comparison of the data in the IAEA, IPEMB, DIN and NCS dosimetry protocols Phys Med Biol 45:563-75

Pesarin F and Salmaso L 2010 Permutation Tests for Complex Data: Theory, Applications and Software: John Wiley \& Sons, Ltd)

Poludniowski G, Landry G, DeBlois F, Evans PM and Verhaegen F 2009 SpekCalc: a program to calculate photon spectra from tungsten anode x-ray tubes Phys Med Biol 54:N433-8

Puck $\Pi$ and Marcus PI 1956 Action of x-rays on mammalian cells J Exp Med 103:653-66

Rafehi H, Orlowski C, Georgiadis GT, Ververis K, El-Osta A and Karagiannis TC 2011 Clonogenic assay: adherent cells J Vis Exp

Shuryak I, Sun Y and Balajee AS 2016 Advantages of Binomial Likelihood Maximization for Analyzing and Modeling Cell Survival Curves Radiat Res 185:246-56

Trompier F, Baumann M, Barrios L, Gregoire E, Abend M, Ainsbury E, Barnard S, Barquinero JF, Bautista JA, Brzozowska B, Perez-Calatayud J, De Angelis C, Dominguez I, Hadjidekova V, Kulka U, Mateos JC, Meschini R, Monteiro Gil O, Moquet J, Oestreicher U, Montoro Pastor A, Quintens R, Sebastia N, Sommer S, Stoyanov O, Thierens H, Terzoudi G, Villaescusa JI, Vral A, Wojcik A, Zafiropoulos D and Roy L 2016 Investigation of the influence of calibration practices on cytogenetic laboratory performance for dose estimation Int J Radiat Biol 1-9

Wong J, Armour E, Kazanzides P, lordachita I, Tryggestad E, Deng H, Matinfar M, Kennedy C, Liu Z, Chan T, Gray O, Verhaegen F, McNutt T, Ford E and DeWeese TL 2008 High-resolution, small animal radiation research platform with $\mathrm{x}$-ray tomographic guidance capabilities Int $J$ Radiat Oncol Biol Phys 71:1591-9

Yoshizumi T, Brady SL, Robbins ME and Bourland JD 2011 Specific issues in small animal dosimetry and irradiator calibration Int J Radiat Biol 87:1001-10

Zoetelief J, Broerse JJ and Davies RW 1985 Protocol for X-ray dosimetry EULEP Report EUR 9507

Zoetelief J, Broerse JJ, Davies RW, Octave-Prignot M, Rezvani M, Vergara JC and Toni MP 2001 Protocol for X-ray dosimetry in radiobiology Int $J$ Radiat Biol 77:817-35

Zoetelief J and Jansen JT 1997 Calculated energy response correction factors for LiF thermoluminescent dosemeters employed in the seventh EULEP dosimetry intercomparison Phys Med Biol 42:1491-504 
Table 1. Variation of the dose measured on radiochromic films for three conditions of irradiation

Figure 1. Dosimetry protocol takes in place on the SARRP irradiator.

Figure 2. Dose profile obtained with the SARRP irradiator without a collimator at the reference position.

Figure 3. Panel A: Irradiation field at the reference position for the 6-well microplate configuration. Panel B: Irradiation field at the reference position measured with EBT3 radiochromic film. To avoid errors induced by plate positioning, only 4 wells have been considered for irradiation. The two remaining wells are filled with water.

Figure 4. Simulated energy spectra obtained at $80 \mathrm{kV}$ with SpekCalc software for the two additional filtrations available on the SARRP, $1 \mathrm{~mm}$ aluminum (red curve) and $0.15 \mathrm{~mm}$ copper (blue curve).

Figure 5. Panel A: Survival curves of HUVECs irradiated from 0 to $4 \mathrm{~Gy}$ at the SARRP $\left(80 \mathrm{kV}, 0.63 \mathrm{~Gy} \cdot \mathrm{min}^{-1}\right.$ and copper filtration: configuration 1). Panel B: Survival curves of HUVECs irradiated from 0 to $4 \mathrm{~Gy}$ at the SARRP $\left(80 \mathrm{kV}, 0.63 \mathrm{~Gy} \cdot \mathrm{min}^{-1}\right.$ and aluminum filtration: configuration 2). For both panels, green curves correspond to the reference condition ( $3 \mathrm{~mL} /$ well), dotted red curves to $1 \mathrm{~mL} /$ well and plain red curves to $9 \mathrm{~mL} /$ well . Panel C: plain green curve represents the reference condition ( $3 \mathrm{~mL} /$ well) for configuration 1 , dotted green curve represent the reference condition $(3 \mathrm{~mL} /$ well) for configuration 2 . For all the panels, each curve represents data from 4 independent experiments, each experiment including 4 wells per dose.

Figure 6. Panels A and B: Survival curves of HUVECs irradiated from 0 to $4 \mathrm{~Gy}$ at the SARRP ( $80 \mathrm{kV}, 0.63 \mathrm{~Gy} \cdot \mathrm{min}^{-1}$ and copper filtration: configuration 1). For both panels, green curves represent the reference condition ( $3 \mathrm{~mL} /$ well). Red curves represent data measured for 
$1 \mathrm{~mL} /$ well (Panel A) or $9 \mathrm{~mL} /$ well (Panel B) while blue curves represent the same data as red curves but taking into account the error in the physical dose for $1 \mathrm{~mL} /$ well (Panel A) or $9 \mathrm{~mL} /$ well (Panel B). Panels C and D: Survival curves of HUVECs irradiated from 0 to 4 Gy at the SARRP $\left(80 \mathrm{kV}, 0.63 \mathrm{~Gy} \cdot \mathrm{min}^{-1}\right.$ and aluminum filtration: configuration 2$)$. For both panels, green curves represent the reference condition $(3 \mathrm{~mL} /$ well $)$. Red curves represent data measured for $1 \mathrm{~mL} /$ well (Panel A) or $9 \mathrm{~mL} /$ well (Panel B) while blue curves represent the same data as red curves but taking into account the correction of the physical dose for $1 \mathrm{~mL} /$ well (Panel C) or $9 \mathrm{~mL} /$ well (Panel D). Each curve represents data from 4 independent experiments, each experiment including 4 wells per dose.

Supplementary data I: Calibration curves obtained with EBT3 films for aluminum and copper filtration.

Supplementary II: HVL values obtained on the SARRP irradiator for the two additional filtrations for different HT.

Supplementary data III: Example of HUVEC clones obtained after irradiation at 2 Gy with configuration 2 in reference condition at $3 \mathrm{~mL} /$ well (Panel A), with $1 \mathrm{~mL} /$ well (Panel B) and $9 \mathrm{~mL} /$ well (Panel C). Microplates represent one representative experiment among four independent experiences 


\section{Figure 1}

Step 1: Dose rate measurement in cell container with ionization chamber calibrated in Air Kerma

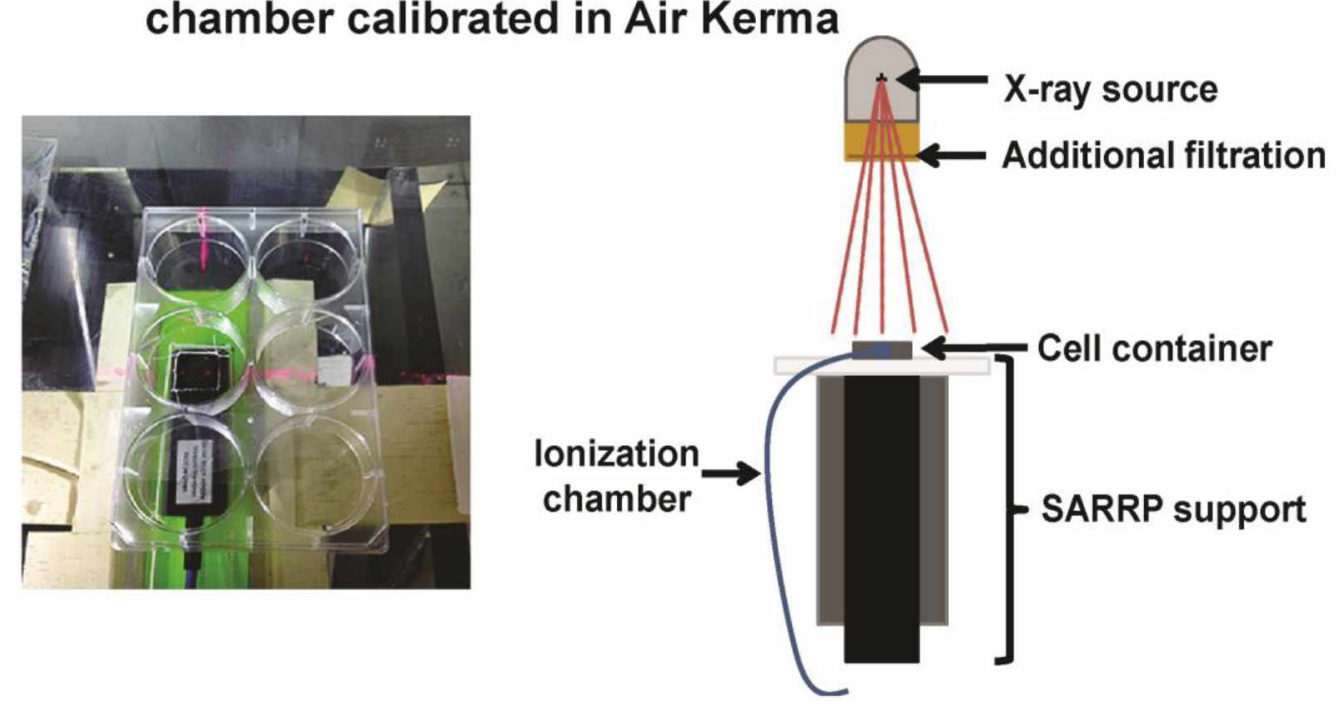

Step 2: Quantification of attenuation due to cell culture medium with EBT3 films
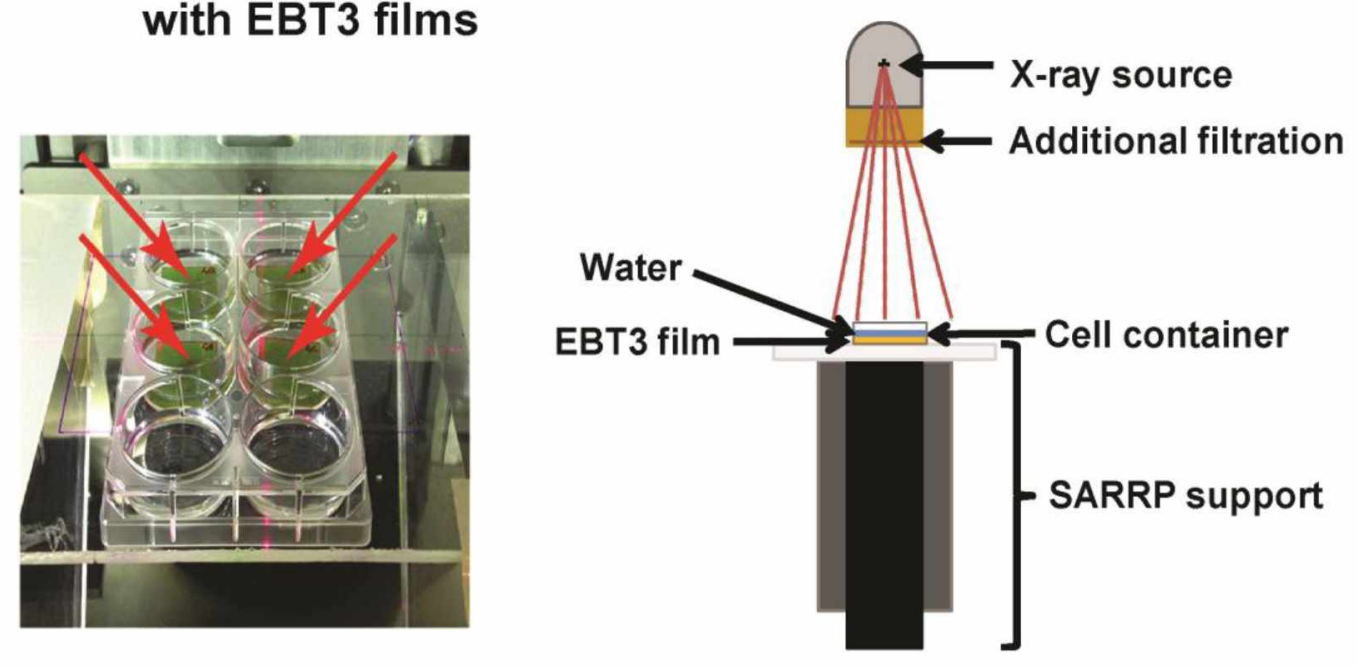

Figure 1. Dosimetry protocol takes in place on the SARRP irradiator 


\section{Figure 2}

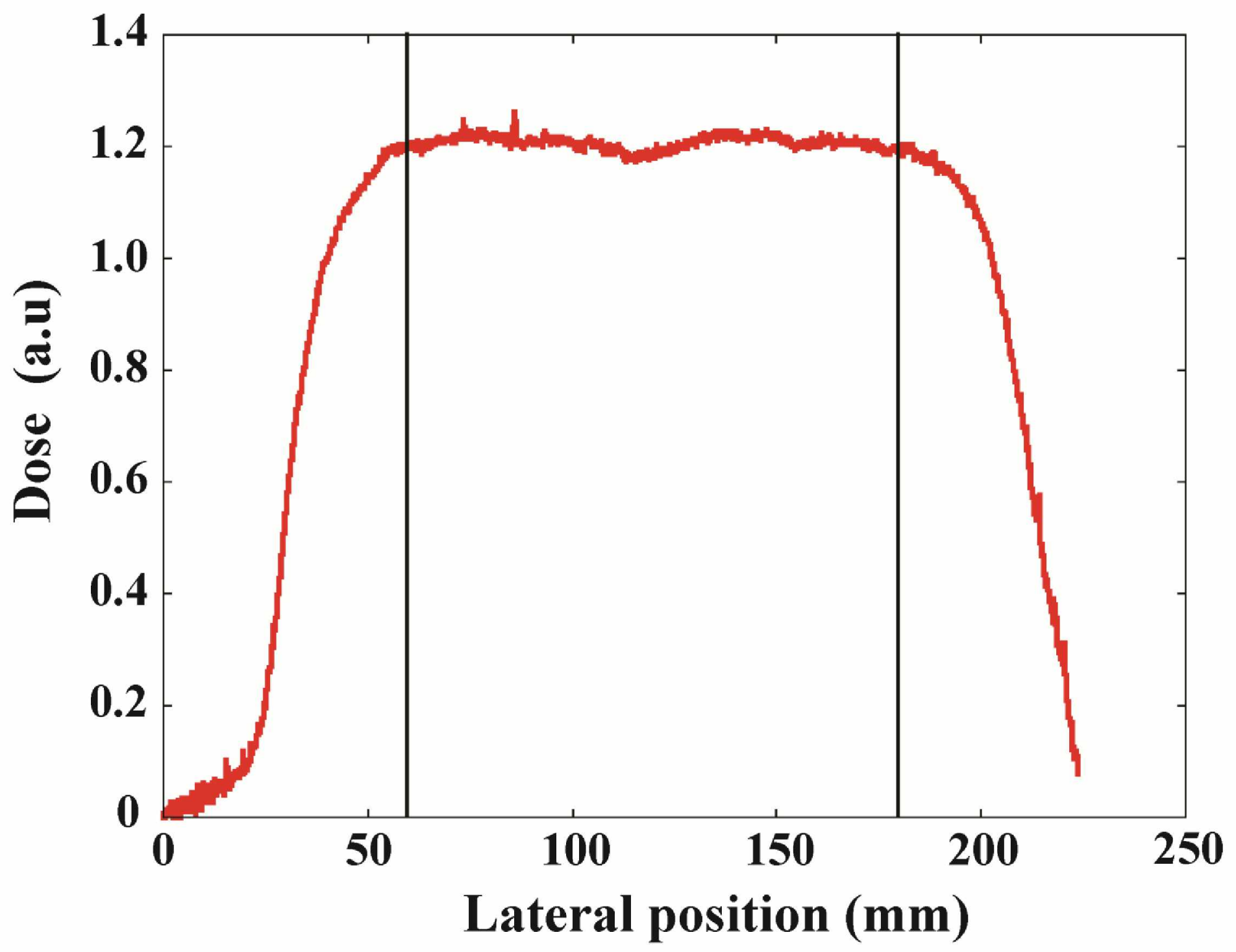

Figure 2. Dose profile obtained with the SARRP irradiator without a collimator at the reference position. 


\section{Figure 3}

$\mathbf{A}$

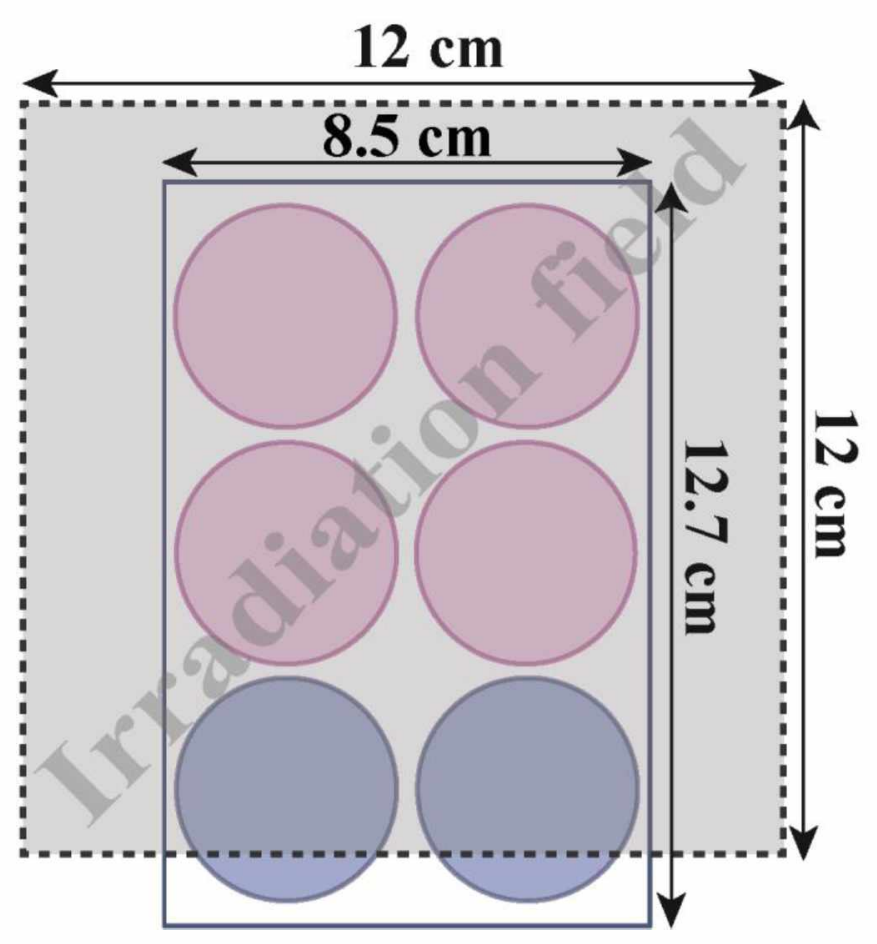

B

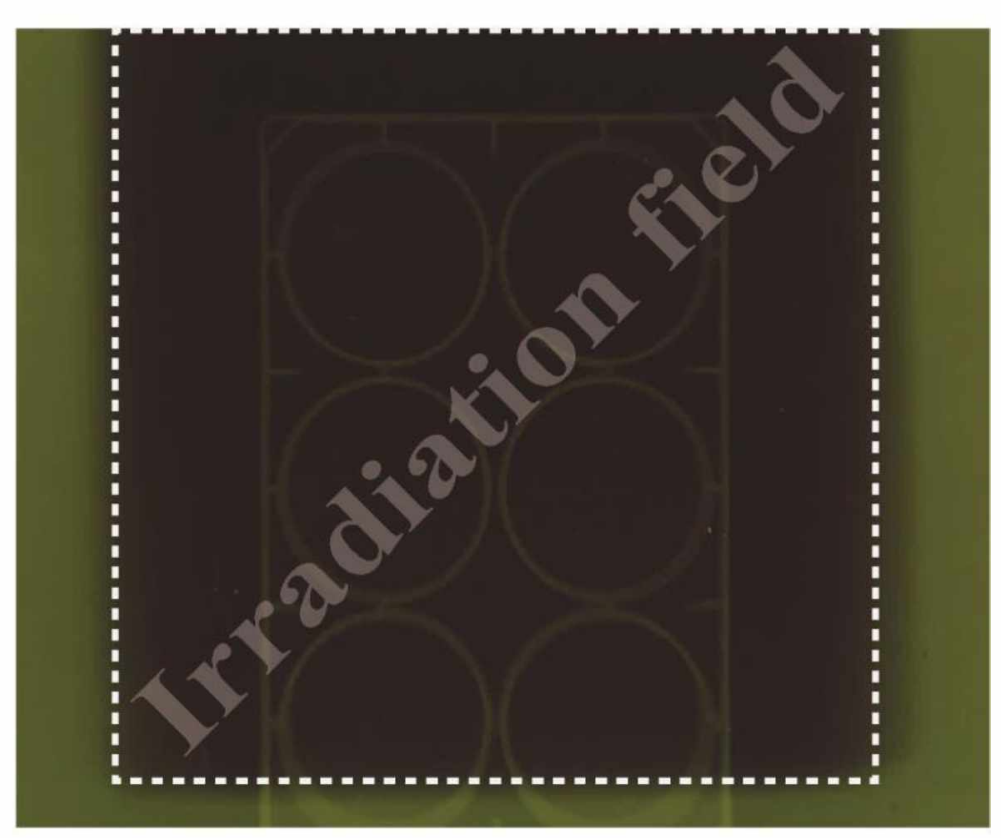

Figure 3. Panel A: Irradiation field at the reference position for the 6-well microplate configuration. Panel B: Irradiation field at the reference position measured with EBT3 radiochromic film. To avoid errors induced by plate positioning, only 4 wells have been considered for irradiation. The two remaining wells are filled with water. 
Figure 4

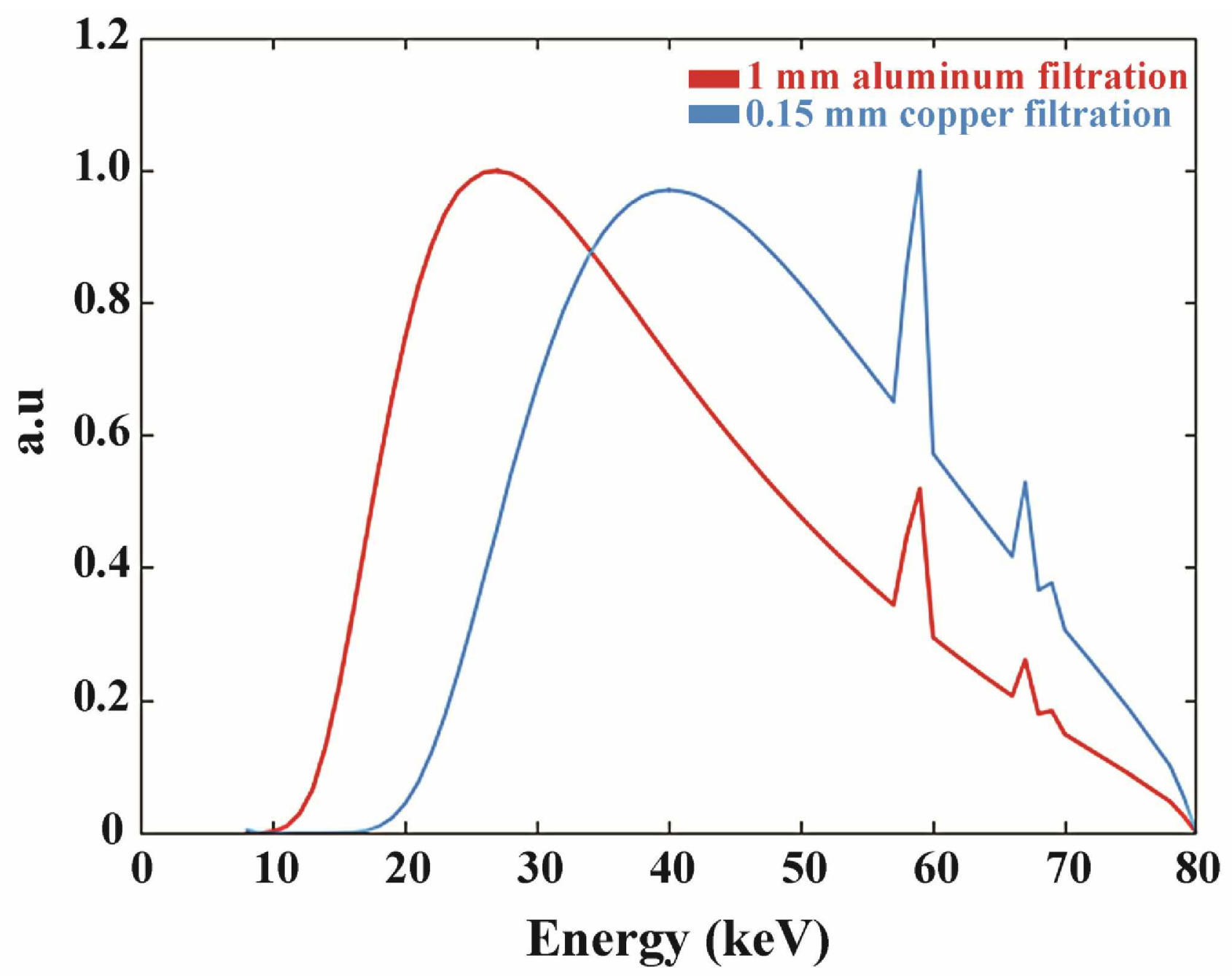

Figure 4. Simulated energy spectra obtained at $80 \mathrm{kV}$ with SpekCalc software for the two additional filtrations available on the SARRP, $1 \mathrm{~mm}$ aluminum (red curve) and $0.15 \mathrm{~mm}$ copper (blue curve). 

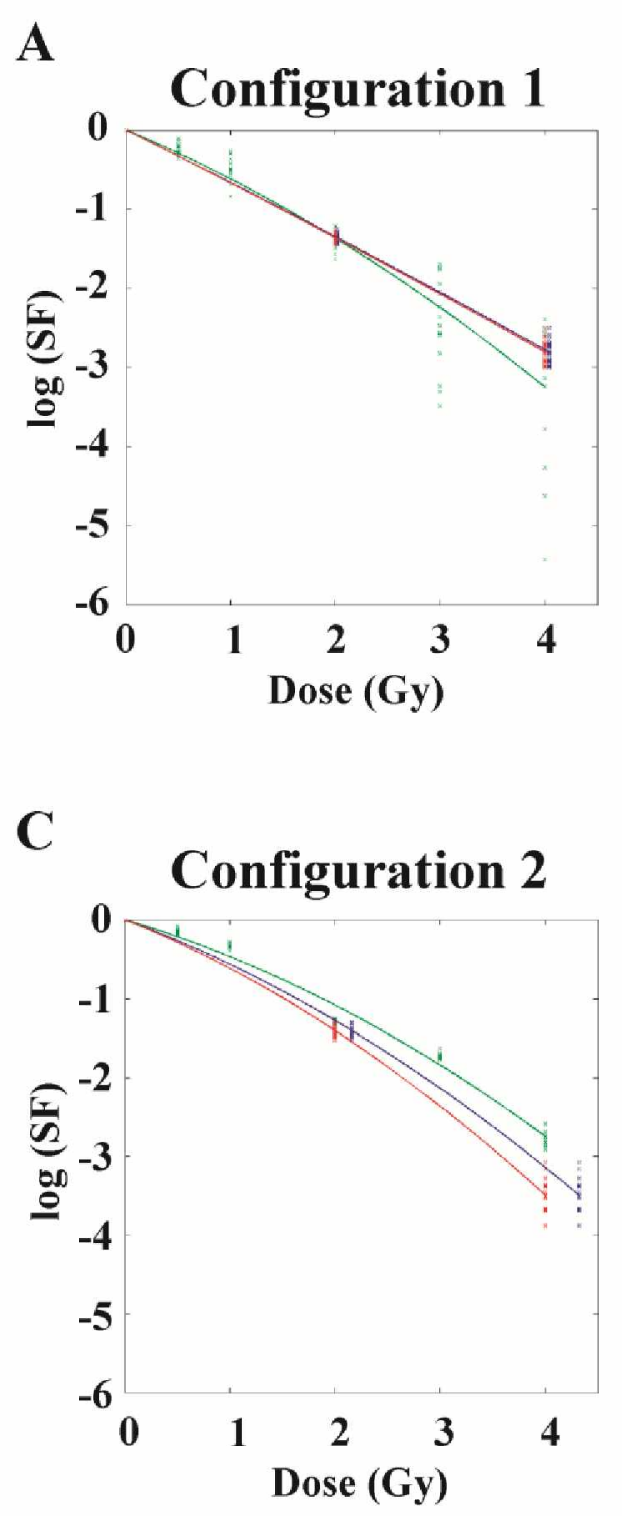
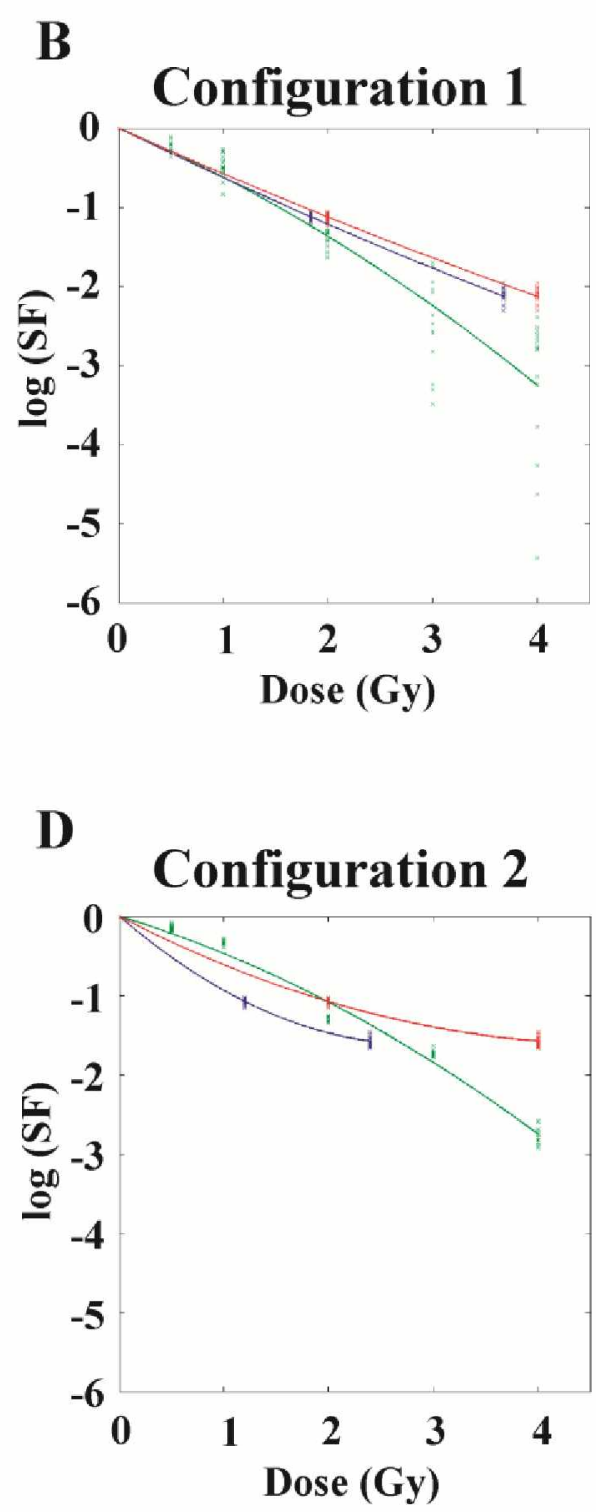

Figure 6. Panels A and B: Survival curves of HUVECs irradiated from 0 to $4 \mathrm{~Gy}$ at the SARRP (80 kV, $0.63 \mathrm{~Gy}_{\mathrm{min}} \mathrm{m}^{-1}$ and copper filtration: configuration 1). For both panels, green curves represent the reference condition (3 $\mathrm{mL} / \mathrm{well})$. Red curves represent data measured for $1 \mathrm{~mL} /$ well (Panel A) or $9 \mathrm{~mL} /$ well (Panel B) while blue curves represent the same data as red curves but taking into account the error in the physical dose for $1 \mathrm{~mL} /$ well (Panel A) or $9 \mathrm{~mL} /$ well (Panel B). Panels C and D: Survival curves of HUVECs irradiated from 0 to $4 \mathrm{~Gy}$ at the SARRP (80 kV, 0.63 Gy. $\mathrm{min}^{-1}$ and aluminum filtration: configuration 2 ). For both panels, green curves represent the reference condition (3 $\mathrm{mL} /$ well). Red curves represent data measured for $1 \mathrm{~mL} /$ well (Panel A) or $9 \mathrm{~mL} /$ well (Panel B) while blue curves represent the same data as red curves but taking into account the correction of the physical dose for $1 \mathrm{~mL} /$ well (Panel C) or $9 \mathrm{~mL} /$ well (Panel D). Each curve represents data from 4 independent experiments, each experiment including 4 wells per dose. 
Supplementary data I:

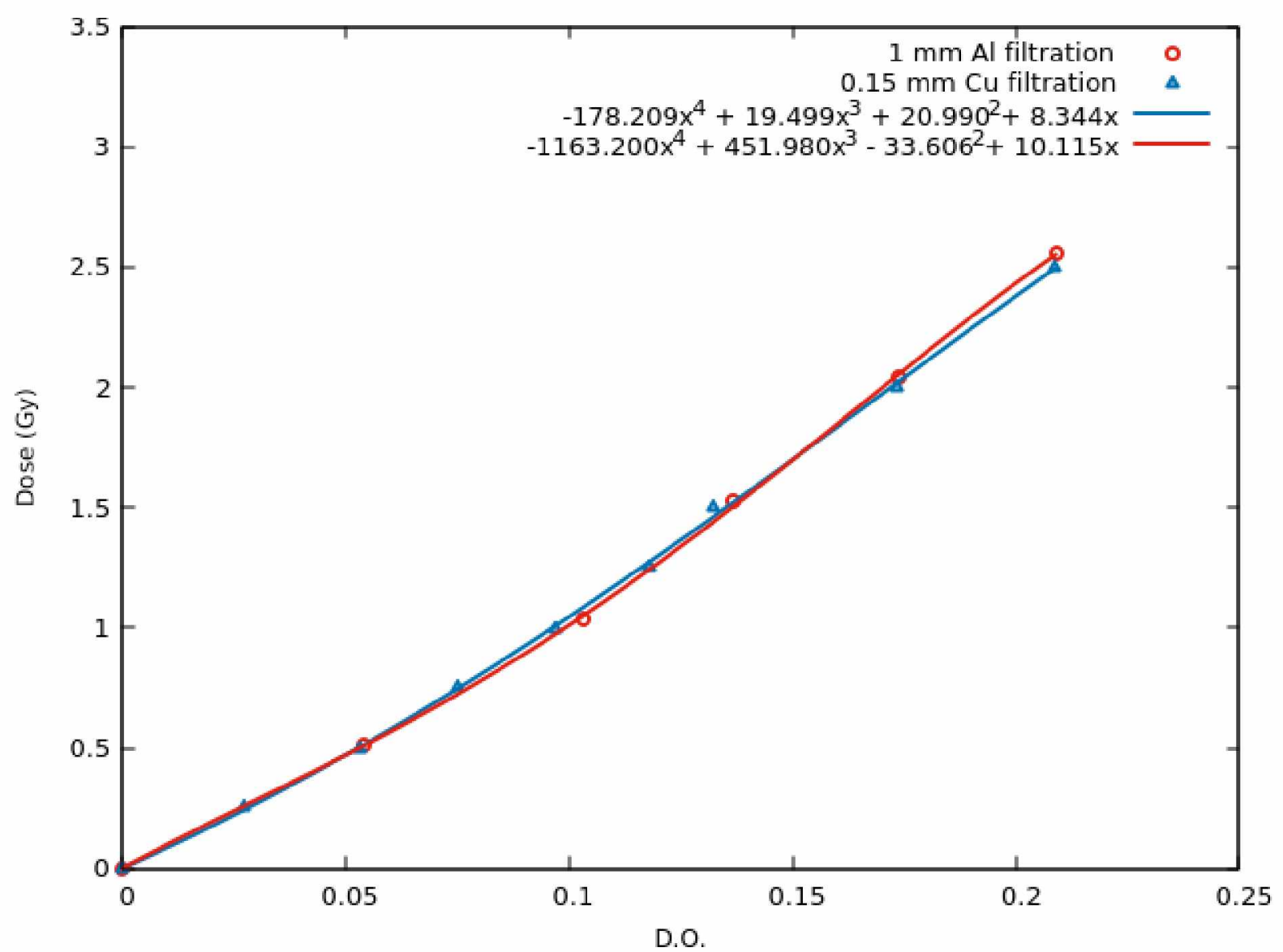

Calibration curves obtained with EBT3 films for aluminum and copper filtration. 
Supplementary data II:

HVL values obtained on the SARRP irradiator for the two additional filtrations for different HT.

Additional filtration: $1 \mathrm{~mm} \quad$ Additional filtration: $0.15 \mathrm{~mm}$ copper aluminum

\begin{tabular}{ccccc}
\hline $\begin{array}{c}\text { High Voltage } \\
(\mathrm{HV})\end{array}$ & HVL mm Cu & HVL mm Al & HVL mm Cu & HVL mm Al \\
\hline 40 & 0.028 & 0.852 & 0.055 & 1.344 \\
\hline 70 & 0.044 & 1.339 & - & 3.218 \\
\hline 80 & 0.056 & 1.520 & 0.138 & 3.724 \\
\hline 100 & 0.070 & 1.908 & 0.198 & 4.748 \\
\hline 120 & 0.103 & 2.525 & 0.276 & 5.852 \\
\hline 150 & 0.128 & 3.302 & 0.366 & - \\
\hline 180 & 0.187 & 4.173 & 0.461 & - \\
\hline 220 & 0.282 & 5.420 & 0.667 & - \\
\hline
\end{tabular}


Supplementary data III:

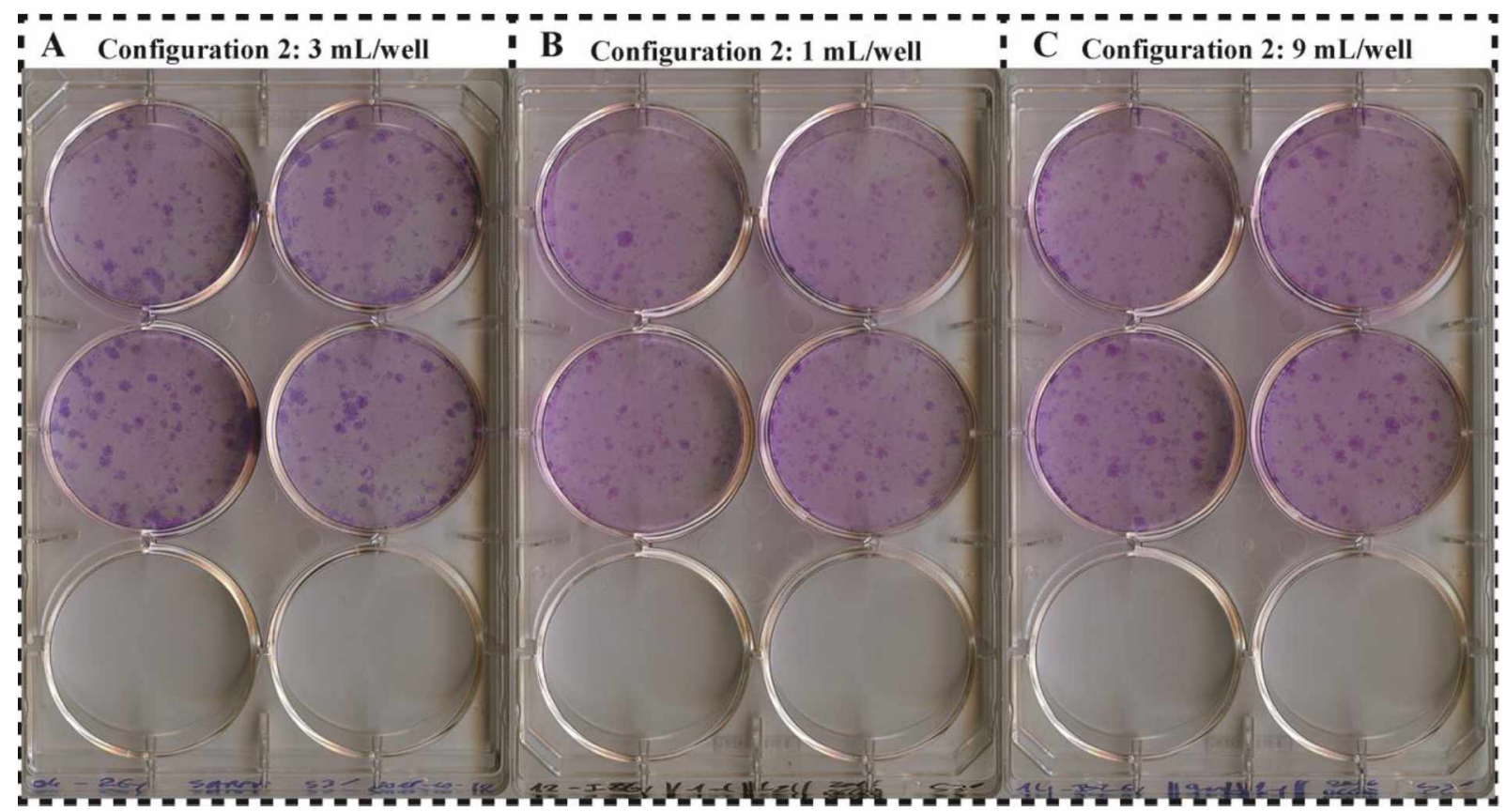

Example of HUVEC clones obtained after irradiation at $2 \mathrm{~Gy}$ with configuration 2 in reference condition at $3 \mathrm{~mL} /$ well (Panel A), with $1 \mathrm{~mL} /$ well (Panel B) and $9 \mathrm{~mL} /$ well (Panel C). Microplates represent one representative experiment among four independent experiences 